\title{
On Dramaturgy of Russian Romances of S.V. Rachmaninov
}

\author{
Li Eryong \\ Department of Music, Musicology, College of Arts, Jiangxi University of Finance and \\ Economics, Nanchan, China. E-mail: li.eryong@uoel.uk
}

\begin{abstract}
The relevance of the study is determined by the fact that the main field of Rachmaninov's vocal creativity was lyrics, the world of personal feelings and moods. In its origins, it is associated mainly with Tchaikovsky's legacy, which is also manifested in the general emotional "openness", sincerity and immediacy of expression, and in some more specific stylistic characters. The novelty of the study determines that, like Tchaikovsky, Rachmaninov sought above all to capture the basic mood of a poetic text in a bright melodic image, showing it in growth, dynamics and development. Therefore, there are those long lines of rise, growth and pathetic climax, which Rachmaninov's romances abound with. The authors show that he did not miss the experience of the senior masters of the "St. Petersburg school" with their careful, attentive attitude to the poetic word. Rachmaninov, with some rare exceptions, does not allow arbitrary permutations of words or repetitions that violate the form of the verse, his vocal declamation, as a rule, is accurate and distinct. In this regard, he was quite at the level of his time - the era of the highest, most refined poetic culture. The practical significance of the research is determined by the fact that the study of the heritage of the art of Rachmaninov will be important for the general study of the flow of musical culture of the period under study.
\end{abstract}

Keywords: Rachmaninov, musical culture, romance, composer, heritage.

\section{Introduction}

Sergey Vasilyevich Rachmaninov is a unique figure in the world musical culture of the end of the 19th and early 2oth centuries, a brilliant composer, conductor, and pianist. Composer's chambervocal creativity is a recognised part of the present vocal repertoire. S. Rachmaninov wrote more than 8 romances (op. $4-6$ romances op. 8 - 6 romances op. 14 - 12 romances op. 21 - 12 romances op. $26-15$ romances op. $34-14$ romances op. $36-6$ romances; 12 romances the composer did not combine in cycles). Romances op. 38 occupy a special place in the composer's vocal heritage. This cycle was written in the fall of 1916. Romances of S. Rachmaninov op. 38 carry in themselves not only the complex concept of perception of a turbulent time, these romances are the last in the composer's chamber-vocal genre. The reference to the texts of the Symbolist poets (Valery Bryusov, Andrei Bely, Fedor Sologub, Konstantin Balmont, Alexander Blok, Igor Severyanin) was not accidental. This reflected the ideological tendencies of capturing and studying one of the leading literary and artistic trends of that time - symbolism. S. Rachmaninov has already addressed the images of the Symbolists: the symphonic poem "The Isle of the Dead" (op. 29, 1909), the poem "The Bells" based on poems E. Poe, translated by K. Balmont (op. 35, 1913), the design of the opera "Monna Vanna" by Maeterlinck.

Texts for vocal opus were proposed by the composer N. Shaginyan. These were 15 poems by M. Lermontov and 26 poems of the "new poets". The expressive artistic kinship of the poetic texts

(c) AesthetixMS 2021. This Open Access article is published under a Creative Commons Attribution Non-Commercial 4.0 International License (http://creativecommons.org/licenses/by-nc/4.o/), which permits non-commercial re-use, distribution, and reproduction in any medium, provided the original work is properly cited. For citation use the DOI. For commercial re-use, please contact editor@rupkatha.com. 
chosen by the composer, a priori, was due to their inherent general ideological accentuation, corresponding to the figurative and symbolic attitude of their authors.

\section{Literature review}

The extensive range of images and related emotional states is revealed in the composer's artistic plan through the prism of loneliness, impulse and appeal to nowhere (Biesold, 2003). This emotional mood reflects changes in the artist's creative worldview: emotional openness, carelessness, and enthusiasm characteristic of S. Rachmaninov's early romances changed in the last vocal opus on the fragility, elusiveness of the emotional state, the prevalence of restless images, ghostly and painfully pointed (Goldfine, 2018). The vocal melody, devoid of breadth of deployment and flexible plastics inherent in the Rachmaninov melos of the early period, becomes structurally open, short in breathing (Rachmaninov, 1956). The vocalist needs to have considerable professional skill in order to convey a complex intonation, brittle, graphic melody, which can vary from dry recitation to rich pathos and dramatically heightened expression (Phillips, 1990). All this is the reason that the cycle of romances op. 38 is extremely difficult to perform (Miller, 2013).

The functional and role rethinking of the piano part, the imaginative range of which in the analysed cycle is extremely voluminous and extensive, also determines noticeable complexity of vocal technique (Chigareva, 2016).

The complexity of the piano accompaniment is also emphasised by the semantic polyvariance of the textural presentation, which in its dramatic scale is equal to the textural architectonics of the plot-unfolded opera scenes (Rachmaninov, 1901). Such, at first sight, somewhat hyperbolic comparison is by no means an exaggeration (Shorluyan, 2015). The expediency of its use is proved by the presence in the Rachmaninov op. 38 of the autonomous system of linear-polyphonic and chord-harmonic intonation, which, in the end, causes the diversified expansion of the keyboard space (Rachmaninov, 1986). Expressing the content of symbolic poetry, this system reproduces various aspects of an individual psychological states of a human person - from landscape depiction and meditative detachment to strong, almost demonic experiences (Titova, 2003). This once again confirms that a pianist must have an extraordinary performing gift in order to convey all the graphic versatility of this part, the brightness and the incredible coloristic colourfulness of the romance drama, which is the basis of the composer's artistic intention (Wood, 2017).

\section{Materials and methods}

Stylistic changes in the history of art, the birth, development, flourishing and decay - the phenomenon verified by the subsequent time (Barrie, 1990). Transition periods enhance the integrative processes eroding the genre-style space of art. At such times, the cultural process allegedly opens, becomes more sensitive to the perception of a new, fresh, unprecedented, even shocking. Truly, transition periods are a blessed time for creative search (Tsiyun, 2018). This is the time when communicative tendencies become aggravated, so-called "open zones" are formed, in which new creative ideas mature. By building a personal world of artistic symbols against a background of life observations, an artist becomes the creator of the Epoch Symbol (Spist, 2015)

Chamber-vocal creativity in the current history of the system of genre-style musical palette is the most intimate manifestation of the psycho-emotional face of being. This genre model is based 
on a poetic text, where the richness of lyrical imagery is highlighted (Norris, 2000). This factor forms the introspective orientation of the genre. The variety of forms and semantic possibilities of music allow it revealing different types of relationships. Vocal music is capable to reproduce visual images, has a descriptive character, can be conflicted and personalised, which enhances its dramatic qualities, and can also reveal personality-subjective features (Riesemann, 1970). The latter gives an intimate connotation to a lyrical utterance, moving into the sphere of psychological metamorphosis of artistic creativity (Emilio, 2017).

On the break of historical epochs, a lyric utterance of an artist has a weighty meaning (Queenan, 2007). The contribution to contacts with diverse cultures and the openness of an artistic process lend the introvertive genres a mystical and prophetic tone. In a lyrical utterance, as in no other, an artist reaches the extreme degree of focusing on an extramusical idea.

\section{Results and discussion}

In 1941, S.V. Rachmaninov gave an interview in which he asserted that extra-musical impressions help him in the process of creating music.

But "this does not mean that I write descriptive music... Ultimately, music is an expression of the composer's individuality in its entirety... The composer's music must express the spirit of the country in which he was born, his love, his faith and thoughts that have arisen under the impression of books, paintings that he loves. It should be a synthesis of the composer's entire life experience."

This expression is heavy. It is not typical for the composer. Rachmaninov was always sure that the music talked about him, his aesthetic views, and his feelings quite meaningfully. Chamber-vocal creativity is a mirror of the composer's soul. The "voice of the author" in chamber music is heard in the so-called "key words" - intonations, the meaning of which manifests itself through both literal and variable repetition. Author's intonations are consolidated on one or several themes. It creates the effect of the presence of the author in the middle of a musical work, as one of the characters in the storyline, with whom he identifies himself, endowing him with his thoughts and feelings.

Rachmaninov's music is full of self-observation, self-description, self-reflection, it is often a self-portrait. It contains monologues and dialogues with his alter ego. The composer seems to be trying to verify personal experience in the realm of the senses. He builds his lexical complex, represents his artistic outlook.

In the system of the composer's leitmotif complexes a special role belongs to the leitmotif "I". The key to the disclosure of this complex can be the little-known vocal work of Rachmaninov. This is a musical letter addressed to K.S. Stanislavsky. In this "letter" the composer recorded intonation, with which he probably associates his artistic "I". The composition is written on his own prose text, in the traditions of a theatrical skit. The author intentionally does not decorate himself, but endows this intonation with ironic features. The melody of the opus is stingy, plainly simple.

This "letter" provides an opportunity to establish the final connection of the most important intonation with the functional theme present in various variants. This topic, in our opinion, did not appear by chance precisely in the vocal genre. Here the composer, with all the natural spontaneity, had personified the momentous intonation, which he then implemented as a demonstration of his presence. The penetration of this leitmotif into the musical compositions authorises them, gives them the features of autobiography. The author presents himself as the main character. 
It is worth to track leitmotif, which first appeared in a letter to Stanislavsky:

-In vocal part "The letter to K.S. Stanislavsky" it is duplicated in piano accompaniment;

-theme II of the Second Piano Concerto;

-Part III of the Second Concerto is thematically based on the leitmotif "I";

-the initial bars of the third piano concerto;

-the initial bars of the symphonic poem "The Bells".

In the characteristic of chamber-vocal music, the leitmotif "I" has a special meaning. A conscious use of the author-leaked identity theme-symbol is a major factor. In Rachmaninov's postcrisis period, this is one of the compositional tools that provides new properties of the author's style.

It should be noted that in the compositions of the composer the melody is the initial basis, and the creation of the melody is a special gift. This is what marks the talent of the artist. "The melodic phenomenon is examined in a number of teachings on harmony, form, and polyphony. Beginning with antiquity, philosophical and ethical treatises are written on the essence of the melodic beginning. Plato, Aristotle, R. Descartes, J.J. Rousseau, D. Diderot, G. Hegel, and other thinkers expressed interesting ideas on this topic."

The vocal lyrics of Rachmaninov have a great energy potential. The special role of melodic leakage is one of the factors. The secrets of the composer's artistic life will be revealed to us sooner if we follow the motivational factors of the evolution of Rachmaninov's creative method. We were interested in the determinant parameters of vocal sound, which determined the evolutionary processes in the composer's art. The influence of fruitful creative communication with contemporary singers on the qualitative changes in artistic and aesthetic orientations of creativity. The possibility of paradoxical solutions and contamination in creative tandems is growing. The creative community of such personalities as, for example, Rachmaninov and Chaliapin spreads the content of the cultural reality of the era. The variety of vocal lyrics of the early period of creativity, the riot of colours, the "flood of feelings" are gradually transformed into monolithic monologue and ascetic utterances.

The emotional sensuality of the musical images of Rachmaninov's lyric utterance is based on a certain genre typology that has arisen as a result of the genre's evolution. In the history of the Russian romance, genre complexes with semantic characteristics inherent only in them were formed. Each such complex exists according to its own laws and may vary within certain limits. So one of them is called "Russian song". This is an allusive musical composition with the obligatory elements of stylisation of the vocal part, literary basis and piano accompaniment. Accordingly, a metaphor must be present in the poetic text.

In the art of Rachmaninov to the designated genre complex can be attributed romances "I fell in love with my sadness" on the verses of Shevchenko translated by Plescheeva op. 8 No. 4 and "Oh, my field, my little field" on the verses of O. Tolstoy, op. 4 No. 5.

Another type of genre is the gypsy song. The composer fully paid tribute to it in the opera Aleko. The so-called "Cruel" romance is characterised by an extreme manifestation of passions. An example of such a romance in the vocal compositions of Rachmaninov is the romance "Prayer" on the verses of Plescheyev (for Goethe) op. 8 №6.

The favourite genre of lyric utterance is Elegy. The first romance of Glinka - actually elegy "Do not tempt me needlessly" to the verses of Baratynsky.

Rakhmaninov's creative heritage has many elegies: “Oh no, I beg you, don't leave.” Op. 4 No. 1 on the verses of Merezhkovsky; "In the silence of the secret night” op. 4 № 3 on the verses of Fet; 
"How long it's been, my friend" op. 4 No. 6 on the verses of Golenishchev-Kutuzov; "Duma” op. 8 No. 3 on the verses of Shevchenko in the translation of Plescheyev.

Orientalism is a significant layer of Russian music of the XIX century. An example of this genre complex are romances: "She's good as noon" op. 14 No. 9 on the verses of Minsky, "Don't sing, beauty, in front of me" - the romance of op. 4 number 4 on the verses of Pushkin. It should be noted that Glinka and Rimsky-Korsakov have already addressed this verse.

Thanks to Borodin (his musical characteristics of the Polovtsian state in the opera "Prince Igor") the organ point becomes one of the characteristic signs of "eastern" music. In the romance "Do not sing, beauty, in front of me" Rachmaninov uses an organ point fragmentary. The romance "She's good as noon" is performed on the organ point, excluding 2 bars, preceding the second section.

The most significant genre of the composer's lyric utterance is a romance monologue. In the early period of creativity, the influence of Tchaikovsky was felt here, for whom the designated genre was also one of the leading ones. Rachmaninov's genre of lyrical monologue was formed quite early and permeated all his work. But the paradox is that with time the composer refuses all varieties of lyrical utterance, focusing his attention exclusively on a monologue romance. There is a need to identify some of the composer's tendencies to change landmarks in the era of shifts in the artistic space of transitional historical eras using the example of S. Rachmaninov's chamber-vocal work.

“The flood of feelings" - Asafiev's expression - forever leaves Rachmaninov's romance lyrics. His lyrical expression is phenomenally truthful and gracefully sensual. The composer is also subject to another emotional sphere: enchanted peace, concord with being, admiring God's peace. The process of the composer's creativity gradually acquires a new quality, as if he is mythologised. The artist does not feel dependent on vagaries of public, harsh criticism; he is not interested in problems of popularity of the music that he creates. He no longer seeks support. From now on, in his work there are other landmarks. The cycle of personal cognition, in the confluence of the objective subjective, the creative process takes on a confessional character. The creative heritage of Rachmaninov of the period of 1909-1917 is a piercing redemptive confession of the son of time. A brief analysis of musicological studies devoted to the study of the Rachmaninov's style suggests that, despite their richness and validity of many conclusions, the phenomenon of the stylistics of the outstanding Russian composer hides many more unknowns.

It is very important for a concert pianist who is working on the performance of the cycle of romances by S. Rachmaninov op. 38 to realise the directions of genre-style transformations, which are represented in different numbers of the cycle as a set of specific semantic formulas. The funeral march, the motive of the procession in the romance "At night in my garden..."; chime in the miniature "Dream"; dance rhythm and discrepancy between the piano part and the rather complex vocal part of the Pied Piper; barcarole and lullaby accompaniment in "Daisies" and in the romance "To her"; the emotional appeal that personifies culminating development in the romance "Ay!" these are the genre features (more precisely, the genre-semantic formulas) form the performing decisions and determine the intonation and emotional accents when performing the songs and conveying them to a listener.

The pianist-performer of this last Rachmaninov cycle needs to understand and reflect the whole complex set of psychological states - from exaltation, dramatic rise to the stiffness of feelings, nostalgia, loneliness, dead silence through which a human voice desperately tries to break through.

The first performer of this cycle, Nina Pavlovna Koshits (1894-1965), the Russian-American opera and chamber singer, to whom this cycle was devoted, possessed an amazing ability to skilfully 
unite the specified performing aspects. The singer had a strong voice, rare musicality, clear diction, precise phrasing. She was close to the moods of pathetic, lyricism, elegiac and tragic, all these qualities were necessary for $\mathrm{S}$. Rachmaninov for the musical embodiment of the symbolistic poetry of op. 38.

So, it is worth to consider the romances of this cycle in more detail. The first romance "At night in the garden at my place...", written on the verses of A. Blok (from Isahakyan) is a kind of "preamble" of the cycle, the quintessence of everything sorrowful in it. The performers of this miniature need to convey a sharpened expression, melodic flexibility, variability of musical tissue (in this romance the composer does not indicate the time signature). In the work, the author uses the genre variety: mourning marching, horal. The image of the mourning march appears in the romance of Rachmaninov from the very first bars ( $3^{\text {rd }} \mathrm{bar}$ ). The frozen sound of the first bars of the accompaniment is compensated by the intonation and harmonic expression of the vocal part. It is built on declamatory turns, which, in the conditions of observance of the Lento tempo specified by the composer, sound melodiously and melodiously. Extremely complex vocal part. Already from the first measure, the move to a reduced third, and later for an extended second, sets the vocalist a difficult intonation task.

A significant role in the romance is played by the piano part. At first, it performs a purely accompanying function: the choral chords sound soft, complementing the vocal voice. The construction of the piano part by playing on the diminished seventh chord as a semantic sign of drama, has a long tradition of musical classicism. Rachmaninov used the dramatic sound of a reduced seventh chord, as a symbol of suffering. A reduced seventh chord sounds at the end of the first verse of the romance (8th bar), and in a piano loser, filling in all of its sound, and in the upper register splitting into slightly reduced harmonies.

In the second chapter of the romance, the piano part is an independent imaginativeemotional musical layer. It not only accompanies the voice, but also builds the culminating development of the romance (13, 14 bars), reinforced by the chanting of the characteristic dotted figure (the eighth with the dot - thirty-second: bars $7,12,18$ ), as semantics of the tragedy of the sound. This rhythm is characteristic of the ancient genres Chaconne and Passacaglia.

Another semantic formula reveals the dramatic meaning of the romance of S. Rachmaninov - in its culmination (14th cycle). In the piano part, a descending chromatic move (es, d, des, c, h, b, a) sounds throughout the arpeggio texture. The semantics of this formula is characteristic of the ancient tradition of musical rhetoric, which means suffering. The meaning of second-long intonations is extremely great in this romance; they constitute the tone core of both vocal and piano parts.

All three semantic formulas in the Rachmaninov romance perform the function of musical elements of drama and suffering, with the help of which the symbolic images of A. Blok's poetry are revealed. The overall upward direction of melodic development, dramatization of thematic, tone acuteness, unstable spacing, ascending jumps, the precariousness of the triple pulsation, discording piano chords are the main musical and creative means inherent to the composer, and which performers should rethink and use in their interpretation for the disclosure of musical content this romance.

The features of the intense dramatic pathos S. Rachmaninov brings into the musical fabric of the second romance of the cycle - "To Her". The poetic lines of the romance built on the principle of metric freedom determined the uniqueness of the musical interpretation of the poetry of A. Bely. The main problem in the performance of this romance is to feel the musical undertones that lie in 
the ostinato of musical presentation - the silence of call, hopelessness, bitterness, dark selfdeepening.

Of the three stanzas of the poem, the composer creates a two-particle form, where the first climax (11-12 bars) combines two stanzas into one section. The figurative dramaturgy of this romance develops from a state of painful expectation and gloomy forebodings to a passionate pathetic plea and unceasing call to nowhere. As in the first romance, the development of the threesound, tertian motif (1-2 bars), which is first described in the piano part, plays an important role. This freely intonated metro-rhythmic motive is not only an impulse of thematic development of the vocal and piano parts, but also the tone foundation of the work.

At the beginning of the romance, the vocal part duplicates the part of the piano, which is also built primarily on tertian tone, eventually reborn into a passionate, expressive exclamation with very inconvenient for the singer intonation-interval jumps to the triton. In the end, an orderlyequable movement changes in the vocal part of the impetuous, restless ups of the melodic line.

In the second section ( 16 beat), the lyrical and contemplative image causes a new rethinking of the vocal part. Considering this, in piano accompaniment, it is necessary to feel the spatial volume, which is emphasised by the latitude of the register ratios, the textured multilayer.

In the final section of the romance, the piano part is marked by impressionistic colours, expressiveness (water play). Therefore, a concert pianist should reflect the nebula and the uncertainty of the musical fabric of the romance. In this regard, it is of particular importance to observe the corresponding performing touché - touching the keyboard of the instrument, strive to find contact with its sound and be in context with the vibration that occurs.

The final common measure piano postlude (Meno mosso) opens the way to the world of harmony and spiritual purity. A large amount of chromaticity is replaced by diatonic. A pianist should perform the postlude gently, colour all intonation calls with timbre, feel the diversity of the piano recording.

The next romance - "Daisies" op. 38 No. 3 (on the text of Igor Severyanin) - paints a musical picture of bright pastorality, contemplativeness, which replaced the deep psychology with elements of tragedy of previous works. This romance is one of the most popular romances from the op. 38 series - speech intonation clearly prevails over singing. This is due to the fact that the free rhythmic organisation of poetic lines causes the maximum approximation of the melody of the romance to the lingvo-verbal intonemic structure, provoking an almost linguistic flavour of the vocal part.

The emotional and sublime utterance, sincere admiration for the beauty of the modest flowers reveals the aesthetics of symbolism: the daisy is a symbol of Beauty and Perfection, it is an ideal, despite its external secrecy. A simple diatonic melody almost during the whole sound of the romance, as if hovers above the barcarole accompaniment. The metro-rhythmic structure of the melodic line does not coincide with the iambic pentameter of the poems of I. Severyanin, which, in turn, gives the music a rather subtle character.

As in other romances op. 38, the key words and phrases of the poetic text are accentuated by $\mathrm{S}$. Rachmaninov by changing the intonation structure of a melody or by a sharp palatal shift. So, Ges-dur sounds unexpectedly after C-dur's Bright diatonic (vol. 14), bringing emotional revival to the musical fabric of the piece. In the context of the whole op. 38, the romance "Daisies" is perceived as a contrasting episode, which by its figurative separation dramatises the general musical development of the cycle. 
The piano part in this romance is crucial. When it is performed, there is a need to give increased vocal to an instrumental voice, which takes the main component of musical thought. But it is advisable to consider the vocal part as a kind of coloristic undertone to the piano theme, which includes its individual intonation elements. Compliance with such an algorithm of artistic and musical architectonics poses a number of requirements for the accompanist. In particular, he should have the necessary qualities for performance, namely: the vocalisation of the piano melody against the background of the accompanying figurations, the timbre colours, the subtle sound palette, the softness of the sound. These parameters make it possible to reveal the polyrhythmicity of the layers and the triplet of the presentation of the piano part, which give the romance a special trembling and ephemeral elusiveness.

In the middle section, the intonation dismissal of the vocal part takes place, which is emphasised by a large register volume, more developed phrasing, and saturation of heat and light. After a bright climax (17-2oth bars), the melody gradually melts stressing the illusiveness of the image. In the vocal part, language intonations are heard again, which are compensated by nine-tact postlude that carry the feeling of "air", "breath", elegance, filigree, fragility of the image. In the performance of this romance, the pedal is of great significance, which increases the sound-timbral capabilities of the instrument, enhances the articulation of performance.

The fourth romance of the series "Pied Piper" on the text of the poem by Valery Bryusov requires a special skill of tone for both a vocalist and a pianist. The originality of the musical language is due to the originality of the image of the poetic source. The poem of V. Bryusov was based on the medieval legend of the stranger, who fascinated all the rats by playing a flute and sent them from the city that died from their invasion. The music of the romance has a fantastically scherzo, grotesque sarcastic, Mephistophelean flavour, close to the figurative sphere of the piano scherzos-fantasy etudes-paintings of op. 39

"Pied Piper" is the most complex romance in terms of its structure, written in ternary form. A small piano introduction that imitates a sound of a whistle is based on small sharply rhythmic tertian formulas (leitmotif symbol-images that form the rhythmic architectonics of the whole romance). Tertian structure, as the constructive basis of the "Pied Piper" music, is present in the romance in dynamic development: throughout the miniature, the terrible motif sounds sometimes in a melodic movement of the vocal part, then in vertical tone constructions in the form of sixth and third parts, it is enriched by textural intervals via monophony of sixths and quart-sixth chords. The expressively outlined instrumentality of the primary image-symbol gives reason to speak about the instrumentalism of the vocal part of the romance.

Another feature of the "Pied Piper" is the discrepancy between the rather simple, stylised like "folk song" poems by V. Bryusov and an extremely difficult performing vocal part, and a developed and textured rich piano, which shifts the semantic and figurative accents of the poetic text and gives the romance dramatic character.

An accompanist needs to show the tertian tone dialogue, fret aggravation, dynamic differences, staccato rhythmic pattern, while imitating a whistle call. This tertian tone is a portrait characteristic of the Pied Piper, which repeats itself with the words "Trail-la-la-la-la-la" and is a refrain of romance that varies harmoniously and melodically, changing the musical colouring of the piece.

The last two romances of the op are characterised by the colourfulness of the musical embodiment, the colourfulness of the musical language. 38 - "Sleep" on the words of F. Sologub and "Ay" on the words of K. Balmont. 
The image of a dream, an illusion, a desire that captures us with its inaccessibility, is depicted by the sacrament by the composer in his romance "The Dream" by the text of Fyodor Sologub. The work creates impressionistic, multicoloured flavour, feeling of voluminous space. Rachmaninov creates a poetic picture of a fabulous, magical dream that takes the hero to the world of a wonderful, fantastic dream.

The composition begins with a small motif in the piano part, which developes and transforms into a configuration, against which a barcarole-type melody sounds in the bass tessitura of the accompaniment. These intonations will later be heard in the vocal part, which is built on the motivic development of a small range, in the centre of which is the note des. The bar change of the triplet movement and long rhythmic durations in the vocal part give the romance a feeling of static, metric and rhythmic stiffness. Des-dur is the key of the romance that ideally emphasises the textural transformation of the main motive-symbol in the second part of the romance, where the piano part imitates the chime that so often sounds in the works of S. Rachmaninov. In the interlude, which prepares the transition to the second part of the romance of Meno mosso, romance tones appear in the piano part against the background of a complex, multi-layered texture. The intonations of the vocal part develop in context with the piano part, imitating each other. This episode is complex in terms of ensemble: a soloist and pianist must listen and feel each other very carefully, pronouncing the theme equally emphatically expressively, preparing the culmination of the piece (27th beat).

The romance ends with a great piano postlude, which strikes with sound scale and orchestration. The pianist in it must show skill in getting melodies against the background of all the texture, which gradually and transparently dissolves in PP to a haze of sleep.

The final romance of the cycle "Ay" contrasts with the previous ones both in the type of imagery and in its musical embodiment. The main content of the poetic lines of Konstantin Balmont, the text of whom is used in a romance, is characteristic of the art of symbolism with its unfulfilled dream. The emphasis is on the ephemeral elusiveness, the variability of the ideal image. This is a typical example of a symbolic artistic understanding of the image, which the composer reflects in his musical embodiment. The cry "Ay" becomes an emotional impulse for creating an impulsive and texture-rich musical image. The intonation structure of the vocal phrase is devoid of cantilena smoothness of the sound, which brings it closer to a speech utterance. It is necessary to test the performer for the expressive interpretation of the emotional tone of the poetry of $\mathrm{K}$. Balmont. Strengthens the symbolism and tonality of Des-dur, which the composer used in the romance "The Dream", combining the unfulfilled dreams of the ideal with an arch of meaning.

The romance begins with the sound of the piano, which is superimposed on the vocal part. It is like a memory that is gradually visualised in the imagination and explodes with the first culmination of the romance on the words "we will leave", "we will run". It ends with uncertainty in tome, rhythmic brevity in the piano part.

The central section is another facet of the image, which is characterised by timeless immobility, stupor (ostinato piano part, syncopation, polyrhythm, distant chime). In the dynamised reprise, the leithontone of the first movement is rethought and transformed into a hysterical, broken cry "Ay", which will remain unanswered, and only the piano part, like an echo, repeats it in an expanded postlude.

All this is also reflected in the museum component. Museum-estate of S.V. Rachmaninov "Ivanovka" is the largest world centre for the preservation and popularisation of the Russian cultural 
heritage associated with the life and work of the great composer, pianist and conductor Sergei Vasilyevich Rakhmaninov.

Most of the creative heritage of S.V. Rachmaninov is associated with Ivanovka. From June of 1890 to April of 1917, he lived almost every spring, summer and early autumn, and worked in the estate of Ivanovka, which belonged to his relatives Satines. Many composition of the composer were created in Ivanovka. There he was formed as a person and a musician. All this gives Ivanovka the status of a historic memorial, an important centre of Russian musical culture.

The museum was started in 1968 by the organisation of the Museum Room of S. V. Rachmaninov in the club of the collective farm named after. K. Marx. Since February 1978, the Ivanovo Museum has become a branch of the Tambov Regional Museum of Local History. In June 1982, the House-Museum and the monument to the composer were opened. In the following years, a number of park and farm buildings of the estate were recreated, and adjacent ponds were cleaned. In 1990, Saratov architects, under the leadership of A. Yagnyatinsky, developed a project to recreate the main manor house, the White House. The new museum complex opened in September 1995 (Fig. 1).
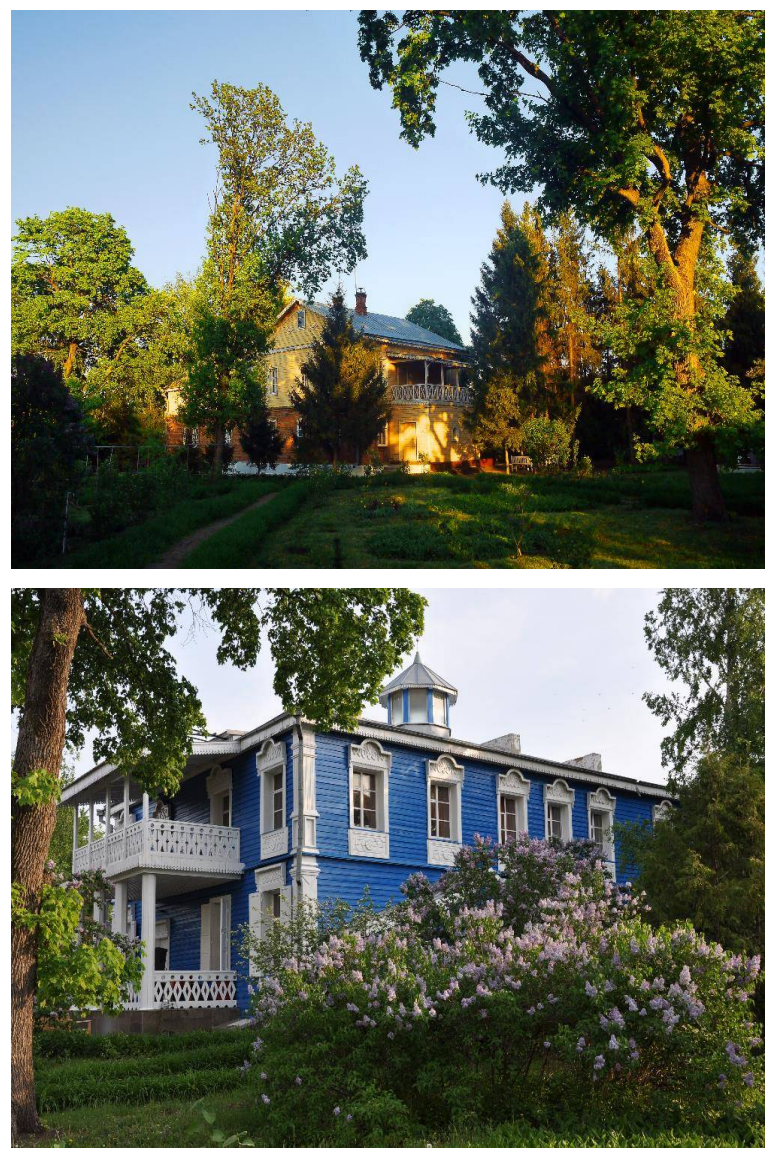

Figure 1: The general exposition of the museum of S.V. Rachmaninov

The area of the estate is 18.5 hectares; the museum area is $1482 \mathrm{~m}^{2}$. The structure of the Museum includes a manor with buildings, a manor park and a pond, branches - "Znamenskoye" Rakhmaninov Family Museum, S.N. Sergeev-Tsensky Museum. In particular, a monument has been erected, which was made in the neoclassical style of Soviet late socialist realism that distinguishes this sculpture from similar forms by other composers. In other similar museums, the main attention 
is paid to the factual mention of the composer, often only the desire for photographic accuracy is reflected in the sculpture. In this case we are talking about the transfer of the musical essence of the composer (Fig. 2). The monument was installed after the collapse of the USSR.

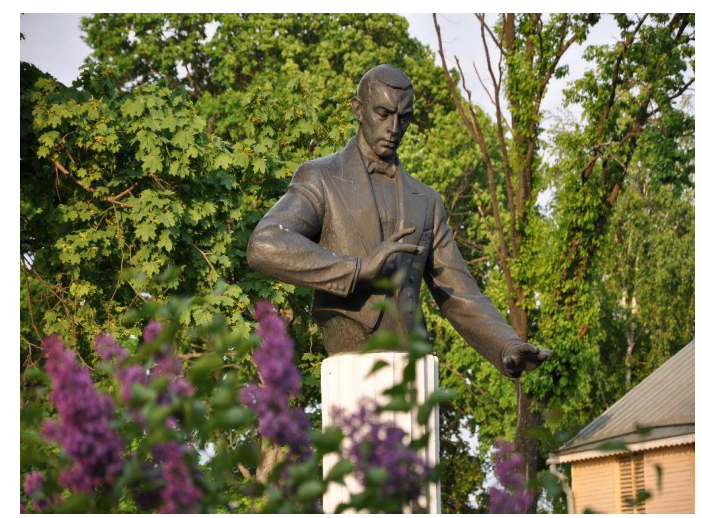

Figure 2: Typological image of S.V. Rachmaninov

The museum successfully implements exposition, concert and festival, and competition projects. To attract visitors, it works with travel companies, conducts registration of marriages in the estate, horses and catamarans are purchased for organizing guests' rest. The existing problems in the work of the Museum are connected with personnel hunger, the lack of the Museum brand and the accompanying advertising and information products, the underdevelopment of the relevant infrastructure (Fig. 3).

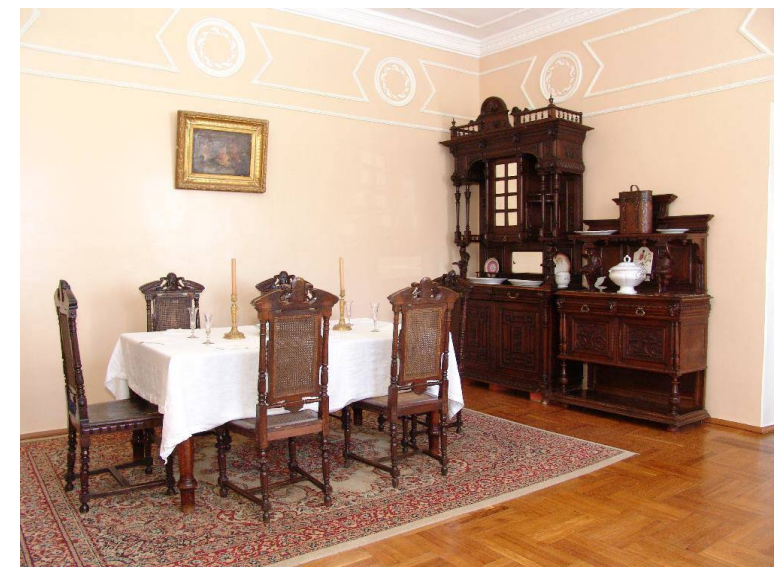

Figure 3: Dining room of S.V. Rachmaninov

Life in the years, when he lived in his house-museum, was difficult. Determined and domineering in performance and creativity, Rachmaninov was by nature a vulnerable person, often experienced self-doubt. He was hindered by material difficulties, everyday disorder, wanderings. And although he was supported by people close to him, first and foremost the Satin family, he felt lonely. The strong shock caused by the failure of his First Symphony performed in St. Petersburg in March 1897, led to a creative crisis. For several years, Rachmaninov composed nothing, but his performing activity as a pianist intensified, and he debuted as the conductor at the Moscow Private Opera (1897). During these years he became acquainted with L. Tolstoy, A. Chekhov, artists of the Art Theatre, began a friendship with Fyodor Chaliapin, whom Rachmaninov considered one "of the most powerful, deep and subtle artistic experiences." In 1899, Rachmaninov first performed abroad (in London), in 1900 he visited Italy, where the sketches of the future opera "Francesca da Rimini" appeared. A happy event was the staging of the opera "Aleko" in St. Petersburg on the occasion of 
the 1ooth anniversary of A. Pushkin with Chaliapin in the part of Aleko. So gradually preparing an internal fracture, and in the early 1900 s he returned to creativity. The new century began with the Second Piano Concerto, which sounded like a mighty alarm. Contemporaries heard in him the voice of Time with its intensity, explosiveness, a sense of future changes. Now the concert genre becomes the leader, it is in it that the main ideas are embodied with the greatest completeness and inclusiveness. In the life of Rachmaninov, a new stage came.

At rehearsals, he often tried to tell people about the new genre and form a new understanding of the mass-everyday genres. However, the implementations of the mass-everyday genres in the works of Rachmaninov are a separate complex and not yet fully investigated problem. We will touch it only to the extent necessary to clarify the causes and motives of the active "second life" of the composer's works in a new, fundamentally different from the academic cultural environment. First of all, it is worth noting that contacts with this environment, with the world of mass music, initially, from the very first opuses, were characteristic of his art. Here, first of all, three related spheres contemporary to the composer should be borne in mind: the dancing element (dance hall), salon and stage. Their "implantation" into the fabric of Rachmaninov's music, as a rule, was distinguished by duality, a kind of balancing between the trivial and the poeticised, in which the trivial did not become the object of parodying, grotesque, and the poeticised did not obscure connections with the everyday fundamental principle. Therefore, the room where S.V. Rachmaninov rehearsed first of all a spacious living room that can be visited simultaneously by several dozen people (Fig. 4).

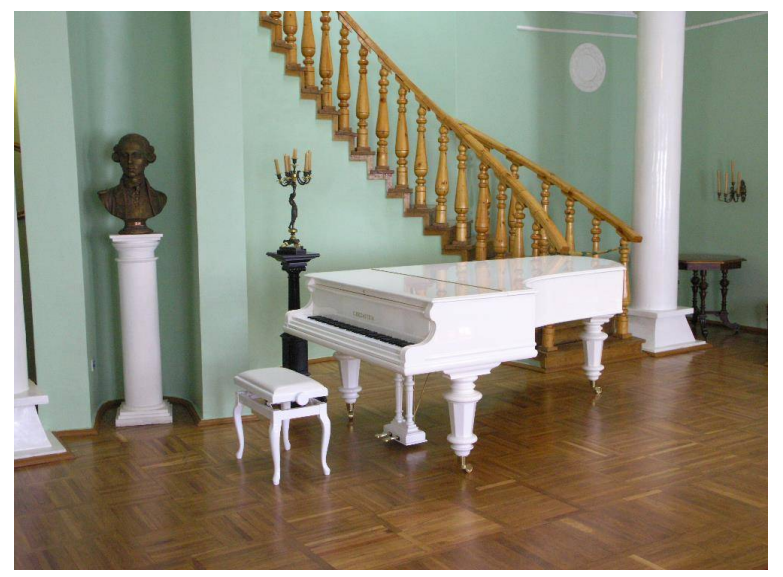

Figure 4: Rehearsal room of S.V. Rachmaninov

The ways in which the composer attained mastery of music and the establishment of bridges between music and a listener were very different. This, with all the innovative aspirations of Rachmaninov, his appeals to the stable, traditional foundations of the genres in which he worked, to their poetic style, that is, to everything that has already firmly entered through the music of the past into the orbit of the listening consciousness. This is the richest melodic gift of the composer, the cantilised-song nature of his thematics, endearing with the vibrant, alive human voice (whether it be vocal music or instrumental), the famous Rachmaninov's "melodies-distances". This, in relation to large-scale works and the way that B. Asafiev defined as the "focus of the form on perception," meaning such musical and compositional logic that would reflect the logic of life and psychological processes. It seems that the exceptional role that the concert genre played in the work of the composer was connected with this focus (of course, in addition to the outstanding Rachmaninov pianism). It was suitable for Rachmaninov because of its direct appeal to the audience, embedded in its genetic code, the element of artistry and the special atmosphere of communication 
with a listener and his involvement. For this, Rachmaninov often not only played concerts, but also formed a space where he could talk with his colleagues in an informal setting (Fig. 5).
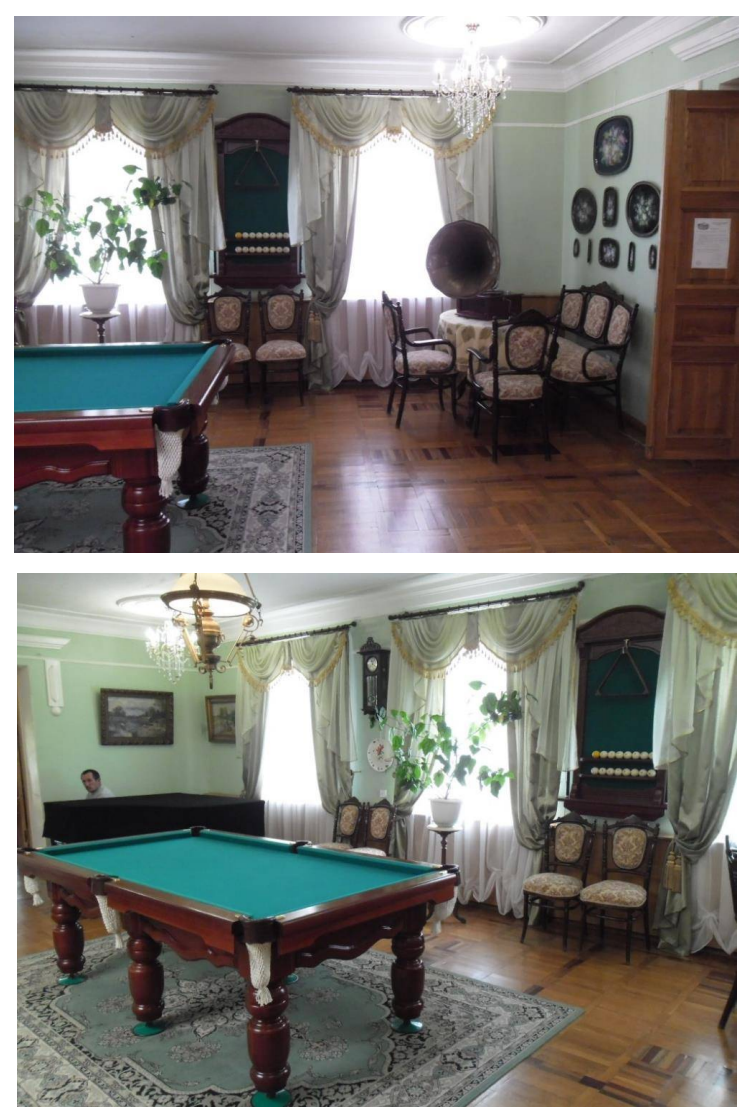

Figure 5: The composition of the recreation area S.V. Rachmaninov

The interiors of many rooms are recreated taking into account the style of the turn of the 19-2oth centuries with the use of furniture of that era, and in some places preserved authentic things are placed (Fig. 6):

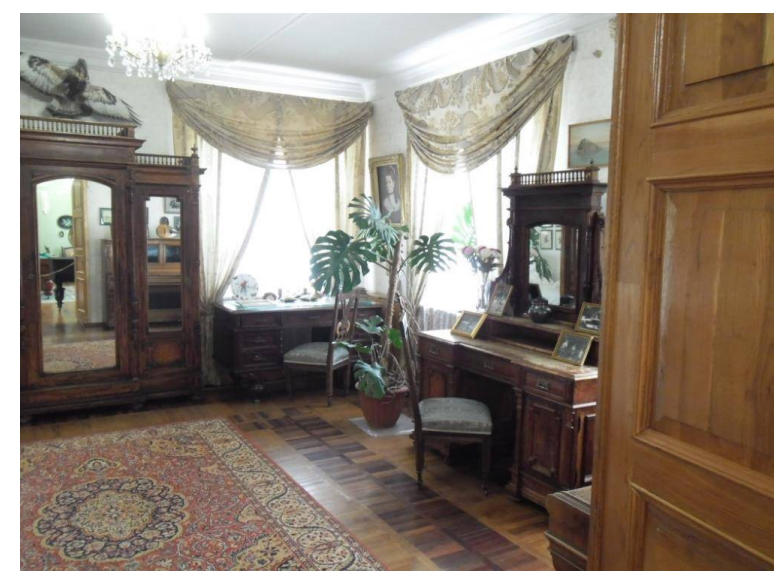

Figure 6: Office of S.V. Rachmaninov

What has been said, however, does not remove the question of why Rachmaninov's music turned out to be so predisposed to live the second, seemingly unusual for it life; how to explain its willingness (apart from the will of its creator) to enter into dialogue with art, as if it is so far? Any 
dialogue (no matter of agreement or disagreement) should satisfy at least two conditions: first, its participants should have common topics they discuss, second, no matter how different the languages in which these discussions take place however, they inevitably should include common lexical elements. Otherwise, no communication (even antagonistic) can occur. Probably, the answer to the question should be sought in these two directions taking into account the informative, semantic parameters of Rachmaninov's music and its genre and stylistic components.

\section{Conclusion}

Having considered each of the individual compositions of op. 38 , it is necessary to identify common factors and patterns that characterise the ratio of the vocal and piano parts, as integral components of the artistic and musical architectonics of the analysed S. Rachmaninov cycle. In all the romances of the cycle, the piano part not only appears in dialogic links with the vocal part, but also frames it with peculiar preludes, postludes and interludes. Almost all six romances of the cycle begin with a small intro (one, two bars) and end with a wide-spread postlude. At the same time, the role of postludes is huge. They are almost obligatory in Rachmaninov's romances. Some of them develop into a whole sound picture ("Daisies" by I. Severyanin, "Dream” by F. Sologub).

The piano part in the songs of S. Rachmaninov is in many ways difficult for a performer. This is conditioned by the fact that it has a number of functions: from primary to conceptual. Thus, in the piano part the logic of dramatic development is often implemented, which reveals the figurative and psychological context of the composition. Due to the emotional and semantic potential embodied in the piano part, Rachmaninov's romances lose their chamber colour, acquiring the hallmarks of a concert chamber-vocal composition. It is necessary for a pianist performing op. 38 to to cover the entire multi-layered, diverse polyrhythmic texture, which is characterised by sudden changes in pace, dynamics and agogics. Considering this, both a vocalist and an accompanist should give each phrase, intonation a character of declamatory expressiveness, which was inherent in the Rachmaninov-pianist. In this context, the characteristic Rachmaninov rubato, delays and postpones of the endings of phrases, sharp rhythmic accents, dynamic contrasts attract attention. Rachmaninov, like none of the other pianists, was able to achieve a smooth melodic cantilena and render the sound of a piano of sensitive beauty and roundness, overcoming the percussion mechanism of the instrument. Therefore, the accompanist's task is to achieve the vocalisation of the piano melody, the diversity of the piano register comparisons, the suddenness of sound solutions. In this context, considerable importance in the romances of op. 38 acquires the multifunctionality of piano pedalling: it participates both in sound and timbral enrichment, and in the formation of large and small structures of piano texture, and in defining articulations, instrumentation, and the like. A conscious emotional and intellectual pronunciation of the musical text by an accompanist will not interfere with the vocalist, and also elicit a singer a necessary creatively enriched sound in return. Subtle, often elusive images of poetic semantic texts determined the semantic richness of the musical text of the composer's romances, with a variety of shades that predict the fullness of the musical expressiveness and content of the romance drama. The ability to decipher it is determined by the ability of performers to "catch" those images, symbols, recorded in the poetic text of poems, which are a kind of key for understanding the music of S. Rachmaninov.

\section{Acknowledgement}

This research is supported by a grant of the Humanities and Social Sciences Fund of Ministry of Education of China (No. 18YJA76003). 


\section{References}

Barrie, M. (1990). Rachmaninoff: Composer, Pianist, Conductor. Cambridge: Scholar Press.

Biesold, M. (2003). Rachmaninov, Sergej Vasil'evič. In: H. Weber (Ed.), Komponisten Lexikon: 350 Werkgeschichtliche Portraits. Stuttgart: J.B. Metzler. 481-482.

Chigareva, E.I. (2016). Rachmaninov and Chekhov (the romance "We will rest"). In: Rachmaninov and the $21^{\text {st }}$ century. Past and present collection of articles. Moscow: Sovetskiy Kompozitor. 210-217.

Emilio, A. (2017). Film/Music Analysis II: Functions and Motivations of Music. In: Film/Music Analysis: A Film Studies Approach. Cham: Springer International Publishing. 125-154.

Goldfine, L.A. (2018). Art of Rachmaninov as an integral part of the musical aesthetics of the "Silver Age". In: G.P. Stulova and A.P. Yudin (Eds.), Art of S.V. Rachmaninov in the performance training of a teachermusician. Materials of the international scientific and practical conference. Moscow: MPGU. 152-156.

Miller, F. (2013). Behind the Camera on Brief Encounter. Turner Classic Movies. Atlanta: Turner Entertainment Networks, Inc.

Norris, G. (2000). Serge Rachmaninoff. In: J.S Stanley and J. Tyrell (Eds.), The New Grove Dictionary of Music and Musicians. London: MacMillan. 707-718.

Phillips, G.D. (1990). Major Film Directors of the American and British Cinema. London: Associated University Presses.

Queenan, J. (2007). Hey, there's an orchestra up here! London: Guardian News and Media Limited.

Rachmaninov, S. V. (1986). Piano Concerto No. 2, Op. 18, and Piano Concerto No. 4, Op. 40. Perf. V.D. Ashkenazy, Royal Concertgebouw Chamber Orchestra. Cond. B.J. Haitink. Decca, CD.

Rachmaninov, S.V. (1901). Concerto No. 2 for Piano and Orchestra in C minor, Op. 18. Boca Raton: Edwin F. Kalmus \& Co, Inc.

Rachmaninov, S.V. (1956). Piano Concerto No. 2. Perf. B. Moiseiwitsch, BBC Symphony Orchestra. Cond. Sir M. Sargent. BBC Labels, CD.

Riesemann, O.A. (1970). Rachmaninoff's Recollections. New York: Arno Press, Inc.

Shorluyan, T.V. (2015). The romance of S.V. Rachmaninov "Dissonance". In: M.S. Agin (Ed.), Issues of vocal education. Methodical recommendations for teachers of universities and secondary specialised educational institutions. Moscow: Nauka. 265-270.

Spist, E.A. (2015). The drama of the musical cycle as a reflection of the interaction of music and words (for example, "Six Poems for Voice and Piano", op. 38 of S. Rachmaninov). Philosophy and Humanities in the Information Society, 2 (8), 77-85.

Titova, E.V. (2003). The romance of S. V. Rachmaninov by the poems of P. A. Vyazemsky, "Did You Have Not". In: Rachmaninov and his contemporaries Collection of articles. St. Petersburg: St. Petersburg State Conservatory named after N.A. Rimsky-Korsakov. 54-68.

Tsiyun, L. (2018). Romance of Rachmaninov “Lilac” (to the problem of performance interpretation). University Scientific Journal, 38, 146-152.

Wood, R.E. (2017). On Music. In: Nature, Artforms, and the World Around Us: An Introduction to the Regions of Aesthetic Experience. Cham: Springer International Publishing. 129-162. 